\title{
Denture as an unexpected cause of obstructive jaundice
}

A 78-year-old woman who presented with jaundice and fever was referred from another hospital to our endoscopy unit. Her laboratory tests revealed a total bilirubin concentration of $11.7 \mu \mathrm{mol} / \mathrm{L}$. Computed tomography (CT) scans revealed dilatation of the main biliary duct and the presence of a foreign body in the peripapillary area ( $\triangleright$ Fig. 1 ). The appearance of the foreign body was suggestive of a denture, and the patient reported having involuntary ingested, 3 days previously, a denture that had been implanted many years ago. We performed an endoscopic retrograde cholangiopancreatography (ERCP), which revealed a protruding papilla with the appearance of an impacted stone. We started to perform a sphincterotomy using a precut needleknife and completed it with a standard sphincterotome. After this, the denture was immediately expelled and allowed to pass into the duodenum ( $\triangleright$ Video 1 ). In the following days, the patient's total bilirubin level decreased and she was discharged home.

Foreign bodies may lead to a wide variety of complications, although the majority of foreign bodies will be passed spontaneously; among the elderly, the most common object is a dental prosthesis [1] To the best of our knowledge, this is the only reported case of an impacted denture causing jaundice. We are unable to explain the possible way in which the denture could have got into the papilla, although such an occurrence is known to be possible because there are other reports of foreign bodies in the biliary tract, including toothpicks and surgical clips [2-4]. The speculated mechanism is reflux from the duodenum [5]. In this case, the sphincterotomy led to a fast resolution of the biliary obstruction and the patient was discharged a few days later. Because the majority of the ingested foreign bodies are unintentional and asymptomatic, the true incidence is diffi-
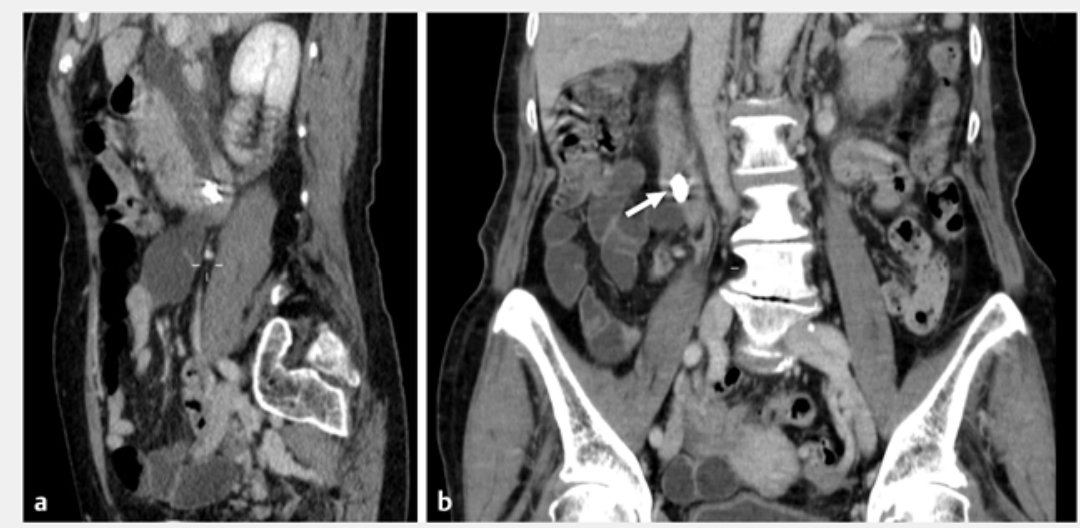

Fig. 1 Computed tomography scans showing: a on sagittal view, dilatation of the main biliary duct and the presence of a foreign body in the peripapillary area; $\mathbf{b}$ on coronal view, the presence of a foreign body in the peripapillary area (arrow).
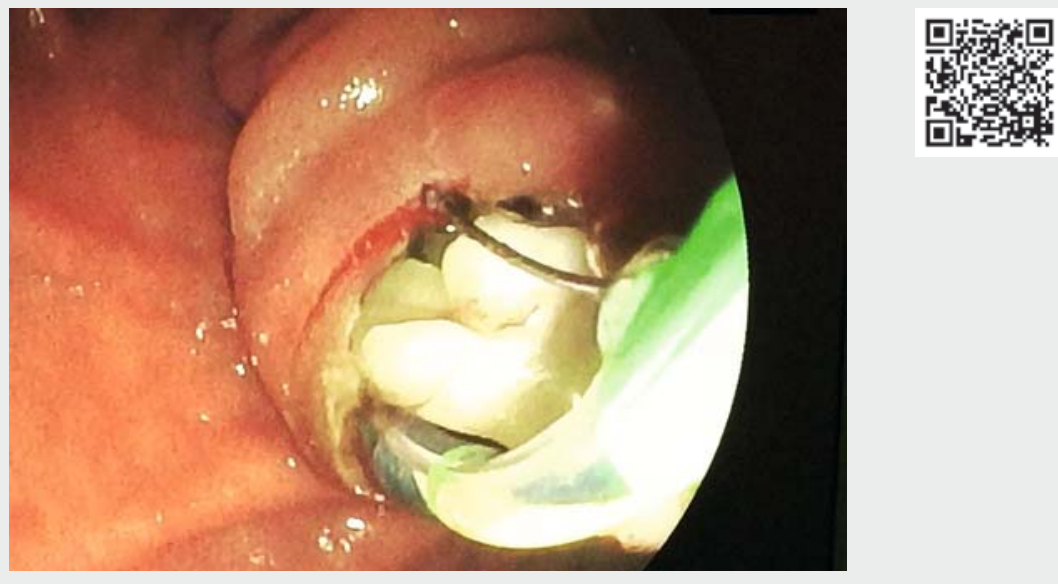

$\checkmark$ Video 1 Endoscopic retrograde cholangiopancreatography in a 78-year-old woman with jaundice and fever showing a protruding papilla and the expulsion of a recently ingested denture following sphincterotomy

cult to evaluate, but we should nevertheless bear in mind the possibility of biliary obstruction being caused by small foreign bodies.

Endoscopy_UCTN_Code_CCL_1AZ_2AI

\section{Competing interests}

The authors declare that they have no conflict of interest. 
Alessandro Pezzoli ${ }^{1}$, Viviana Cifalà ${ }^{1}$, Elena Pizzo $^{2}$, Riccardo Solimando ${ }^{1}$, Loredana Simone ${ }^{1}$, Rosario Arena ${ }^{1}$, Alberto Merighi ${ }^{1}$

1 Department of Gastroenterology and GI Endoscopy, University Hospital Sant'Anna, Ferrara, Italy

2 Department of Applied Health Research, University College London, London, UK

\section{Corresponding author}

\section{Alessandro Pezzoli, MD}

Dept of Gastroenterology and GI Endoscopy, University Hospital Sant'Anna, Via A. Moro n 8 Cona Ferrara, 44100 Ferrara, Italy a.pezzoli@ospfe.it
[1] Ikenberry SO, Jue TL, Dominitz JA. ASGE Standards of Practice Committee. Management of ingested foreign bodies and food impactions. Gastrointest Endosc 2011; 73 : 1085-1091

[2] Ray S, Bhattacharya SP. Endoclip migration into the common bile duct with stone formation: a rare complication after laparoscopic cholecystectomy. J Soc Laparoendosc Surg 2013; 17: 330-332

[3] Brunaldi VO, Brunaldi MO, Masagao R et al. Toothpick inside the common bile duct: a case report and literature review. Case Rep Med 2017; 2017: 5846290

[4] Bargiggia S, Redaelli L, Vailati C et al. Pancreatic pseudotumor caused by toothpick ingestion. Gastrointest Endosc 2015; 82: 179-180

[5] Henderson CT, Engel J, Schlesinger P. Foreign body ingestion: review and suggested guidelines for management. Endoscopy 1987; 19: 68-71
Bibliography

Endoscopy 2021; 53: E472-E473

DOI 10.1055/a-1327-1339

ISSN 0013-726X

published online 4.2.2021

(c) 2021. Thieme. All rights reserved.

Georg Thieme Verlag KG, Rüdigerstraße 14 , 70469 Stuttgart, Germany

\section{ENDOSCOPY E-VIDEOS}

https://eref.thieme.de/e-videos

回回 Endoscopy E-Videos is a free access online section, reporting 回㬐 on interesting cases and new

techniques in gastroenterological endoscopy. All papers include a high quality video and all contributions are freely accessible online.

This section has its own submission website at https://mc.manuscriptcentral.com/e-videos 